\title{
Breast Cancer Diagnostics, Therapy, and Outcomes in Sub-Saharan Africa: A Population-Based Registry Study
}

Walburga Yvonne Joko-Fru, MD, MSc ${ }^{1,2}$; Mirko Griesel, $\mathrm{MD}^{3}$; Nikolaus Christian Simon Mezger, MD³ Lucia Hämmerl, $\mathrm{MD}^{3}$; Tobias Paul Seraphin, MD³; Jana Feuchtner, MD³ ; Henry Wabinga, MD, MMed ${ }^{4}$; Guy N'da, MD, MPH ${ }^{5}$; Assefa Mathewos, MD Bakarou Kamaté, $\mathrm{MD}^{7}$; Judith Nsonde Malanda, $\mathrm{MD}^{8}$; Freddy Houéhanou Rodrigue Gnangnon, MD, MPH?;

Gladys Chebet Chesumbai, BSc ${ }^{10}$; Anne Korir, MD, MPH ${ }^{11}$; Cesaltina Lorenzoni, MD, PhD ${ }^{12,13}$; Annelle Zietsman, MBChB ${ }^{14}$; Margaret Ziona Borok, MBChB ${ }^{15}$; Biying Liu, MSc${ }^{2}$; Christoph Thomssen, MD ${ }^{16}$; Paul McGale, PhD';

Ahmedin Jemal, DVM, PhD ${ }^{17}$; Donald Maxwell Parkin, MD, DSc ${ }^{1,2,18}$; and Eva Johanna Kantelhardt, MD ${ }^{3,16}$

\begin{abstract}
Background: Breast cancer $(B C)$ is the most common cancer in subSaharan Africa (SSA). However, little is known about the actual therapy received by women with $B C$ and their survival outcome at the population level in SSA. This study aims to describe the cancer-directed therapy received by patients with $B C$ at the population level in SSA, compare these results with the NCCN Harmonized Guidelines for SSA (NCCN Harmonized Guidelines), and evaluate the impact on survival. Methods: Random samples of patients with $B C(\geq 40$ patients per registry), diagnosed from 2009 through 2015, were drawn from 11 urban population-based cancer registries from 10 countries (Benin, Congo, Cote d'Ivoire, Ethiopia, Kenya, Mali, Mozambique, Namibia, Uganda, and Zimbabwe). Active methods were used to update the therapy and outcome data of diagnosed patients ("traced patients"). Excess hazards of death by therapy use were modeled in a relative survival context. Results: A total of 809 patients were included. Additional information was traced for 517 patients (63.8\%), and this proportion varied by registry. One in 5 traced patients met the minimum diagnostic criteria (cancer stage and hormone receptor status known) for use of the NCCN Harmonized Guidelines. The hormone receptor status was unknown for $72.5 \%$ of patients. Of the traced patients with stage I-III BC $(n=320), 50.9 \%$ received inadequate or no cancerdirected therapy. Access to therapy differed by registry area. Initiation of adequate therapy and early-stage diagnosis were the most important determinants of survival. Conclusions: Downstaging BC and improving access to diagnostics and care are necessary steps to increase guideline adherence and improve survival for women in SSA. It will also be important to strengthen health systems and facilities for data management in SSA to facilitate patient follow-up and disease surveillance.
\end{abstract}

J Natl Compr Canc Netw, doi: 10.6004/jnccn.2021.7011 Published online December 29, 2021

See JNCCN.org for supplemental online content.

\section{Background}

Breast cancer (BC) is the most common cancer among women in sub-Saharan Africa (SSA) and is the second leading cause of cancer death after cervical cancer. ${ }^{1}$ Approximately 7 in 10 women diagnosed in SSA present with advanced stages of disease (stages III-IV). ${ }^{2}$ Survival among these patients is relatively poor; however, there are survival differences between African countries. ${ }^{3-6}$

$\mathrm{BC}$ treatment is resource-intensive. For nonmetastatic $\mathrm{BC}$, the main pillars of therapy are surgery, radiotherapy (RT), chemotherapy, endocrine therapy (if hormone receptor-positive), and targeted therapies. In SSA, all of these recommended treatment modalities are available in only a few state-of-the-art cancer facilities. Typically, accessibility to such institutions is limited to residents of these areas, those who are covered by health insurance schemes, or those who can afford to pay out-of-pocket. Few African nations have country-specific treatment recommendations, and most often, clinicians offer therapy options based on available local resources. NCCN developed resource-stratified therapy recommendations for

${ }^{1}$ Nuffield Department of Population Health, University of Oxford, and ${ }^{2}$ The African Cancer Registry Network, INCTR African Registry Programme, Oxford, United Kingdom; ${ }^{3}$ Institute of Medical Epidemiology, Biostatistics and Informatics, Martin-Luther-University Halle-Wittenberg, Halle, Germany; ${ }^{4}$ Kampala Cancer Registry, Makerere University School of Medicine, Kampala, Uganda; ${ }^{5}$ Registre des cancers d'Abidjan, Abidjan, Côte d'Ivoire; ${ }^{6}$ Radiotherapy Center, Addis-Ababa-University, Addis Ababa, Ethiopia; ${ }^{7}$ Registre des cancers de Bamako, Bamako, Mali; ${ }^{8}$ Registre des cancers de Brazzaville, Brazzaville, Republic of the Congo; ${ }^{9}$ Registre des cancers de Cotonou, Cotonou, Benin; ${ }^{10}$ Eldoret Cancer Registry, Moi Teaching and Referral Hospital, Eldoret, Kenya; ${ }^{11}$ Nairobi Cancer Registry, Nairobi, Kenya ${ }^{12}$ Maputo City Cancer Registry, Maputo City, Mozambique; ${ }^{13}$ Department of Pathology, Faculty of Medicine, Eduardo Mondlane University, Maputo Central Hospital, Maputo, Mozambique; ${ }^{14}$ Namibian Cancer Registry, Windhoek, Namibia; ${ }^{15}$ Zimbabwe National Cancer Registry, Harare, Zimbabwe; ${ }^{16}$ Department of Gynaecology, Martin-Luther-University HalleWittenberg, Halle, Germany; ${ }^{17}$ Surveillance and Health Services Research, American Cancer Society, Atlanta, Georgia; and ${ }^{18}$ International Agency for Research in Cancer, Lyon, France. 
SSA for the most common cancers ${ }^{7}$ to facilitate therapeutic decision-making for clinicians in resource-constrained settings. There is limited information, however, on whether BC therapy in SSA is concordant with these resource-stratified therapy recommendations.

Most information on BC therapy and survival in SSA is from hospital-based reports, and these describe the survival of patients treated in cancer referral centers. Although these patients receive the best therapy locally available, survival is generally poor. However, what is not known is the experience of the general population of patients with BC in different SSA countries (not only those reaching specialist treatment centers) by way of the therapy received and how this influences survival. To address this knowledge gap, we performed this study including random samples of women from 11 population-based cancer registries (PBCRs) in SSA to describe the cancerdirected therapy (CDT) received at the population level, compare these results to recommended guidelines, and evaluate the impact on survival.

\section{Methods}

\section{Study Design, Population, and Data Source}

This was a retrospective population-based registry study. The sampling frame was the database of the African Cancer Registry Network (AFCRN). ${ }^{8}$ After excluding patients registered based on a death certificate only, we drew random samples of at least 40 patients with BC (per ICD-10, code C50) per registry of patients diagnosed from 2009 to 2015 from 10 PBCRs: Abidjan (Côte d'Ivoire), Bamako (Mali), Brazzaville (Congo), Bulawayo (Zimbabwe), Cotonou (Benin), Eldoret (Kenya), Kampala (Uganda), Maputo (Mozambique), Namibia, and Nairobi (Kenya). In Addis Ababa (Ethiopia), we included all patients diagnosed from January to March 2012. All included patients were African women who were residents of the registry area. The number of randomly selected patients per registry was determined by the practical feasibility of retrospectively tracing health records across multiple centers. All of these PBCRs cover a city, except for the Namibian cancer registry, which covers the national territory. All the registries use the CANREG software developed by the International Agency for Research on Cancer for data entry and for verification checks. Records were traced from the registry to the source of registration, and information on the date of diagnosis and stage was verified or updated and any duplicates excluded (see supplemental eFigure 1, available with this article at JNCCN.org). The registry records were updated with information on diagnostic procedures, treatment received, and patients' vital status from clinical records. However, if this information could not be found in clinical records, then as a last resort the patients or relatives were contacted by registry staff when a contact number was available.

Patients for whom we succeeded in obtaining additional information that was not routinely available in the registry records, from either the source health facilities and/or from reaching patients or their next of kin, are subsequently referred to as "traced patients."

Data management was conducted using SPSS Statistics, version 25 (IBM Corp) and data analyses were performed with STATA, version 14.2 (StataCorp, LP).

\section{Explanatory and Outcome Measures}

The main explanatory variable was the therapy received. The outcome measure was the patients' vital status at the closing date of the study. This measure was ascertained by active follow-up methods as described earlier. The observational time was the time from diagnosis to death, date of last contact, or until the end of the study (December 31 , 2017), whichever occurred first. Patients not found to have died, using the active methods as described, were counted as being alive.

\section{Ethical Considerations}

This study used anonymized and encrypted data from the AFCRN database. The study protocol was approved by the Research Committee of the AFCRN, by the individual registries, and by the Martin-Luther-University HalleWittenberg Review Board (votum number 2019-009). The study complied with the Declaration of Helsinki.

\section{Data Management and Assessing Therapy}

We used the NCCN Harmonized Guidelines for SubSaharan Africa (NCCN Harmonized Guidelines for SSA) for Breast Cancer, version 2.2017, ${ }^{9}$ as a guide for therapy evaluation. Information on stage at diagnosis, hormone receptor status (HRS), and tumor histology are required to use these guidelines for therapy evaluation effectively. To use the same classification categories as the NCCN Harmonized Guidelines for SSA and based on the anatomic stage groupings of the AJCC, we categorized patients into 3 stage groups for therapy evaluation: early BC (stages I, II, and T3N1M0), locally advanced BC (stage IIIA [except T3N1M0], IIIB, and IIIC), and metastatic disease (stage IV, M1). ${ }^{10}$ Patients with early and locally advanced BC are subsequently referred to as "patients with curable or nonmetastatic disease."

For chemotherapy, RT, hormonal therapy, surgery, and targeted therapy, we assessed whether there was documented evidence that the patient had initiated treatment. To assess chemotherapy completeness, we evaluated what proportion of patients received the prescribed chemotherapy regimen. We categorized chemotherapy received as $>85 \%$ complete if the patient received all but one prescribed chemotherapy session, as $\leq 85 \%$ com- 
plete $^{11}$ if the patient had $\geq 2$ missed chemotherapy sessions, and unknown if there was no record of chemotherapy found. We were unable to assess the completeness of RT because the total dose received was not recorded for most patients. Completeness of endocrine therapy could not be assessed because we could not ascertain therapy adherence and completion until year 5 . For surgery, we categorized patients as having received surgery (either a mastectomy or a lumpectomy) or not.

We used a simplified schema based on these guidelines to evaluate the therapy received. Among traced patients with curable $\mathrm{BC}$, we used the categorization below for therapy evaluation:

1. Initiated adequate therapy (the patient received as a minimum): surgery (mastectomy or [lumpectomy $+\mathrm{RT}]$ ) and systemic therapy (chemotherapy and/or endocrine therapy) and/or RT

2. Inadequate therapy (with no curative potential): surgery with no systemic therapy, a therapy combination without surgery, or a monotherapy

3. No therapy: traced patients with no evidence of receiving any CDT

For patients with metastatic disease, we described the therapy they received (see Table 1 for therapies).

\section{Assessing Loss to Follow-Up}

We assessed the proportion of patients lost to follow-up by registry at year 1,3 , and 5 , and used a Cox regression model with loss to follow-up (LTFU) as the outcome, and age and stage at diagnosis as exposure variables to determine whether LTFU was random or associated with either age or stage at diagnosis.

\section{Survival Analyses}

For survival analyses, we excluded patients for whom the date of last contact was the same as the date of diagnosis and who thus had no additional follow-up information. We estimated the all-cause Kaplan-Meier survival for patients by therapy received at year 1,3 , and 5 , and estimated relative survival by age, stage at diagnosis, therapy modality, and country-level Human Development Index (HDI).

\section{Modeling Excess Mortality}

We modeled the excess hazards of death from BC in a framework of generalized linear models using a piecewise Poisson regression model with smoothing splines. We split time into monthly time bands, and adjusted for age, stage at diagnosis, HRS, tumor grade, therapy, and country-level HDI. Registries were grouped by country-level data for parsimony and to improve the power of the multivariable model. All patients with at least 30 days follow-up and with nonmetastatic BC were included. We estimated the relative excess risk of death from curable BC, after considering background mortality. We obtained data on background mortality from 5-year-age abridged WHO Global Health Observatory life-tables, which we expanded from 5 -year ages (eg, ages $0-4,5-9$, and 10-14 years) to single-year ages (eg, ages $0,1,2$, and 3 ) using a Poisson regression model with a flexible function. We performed sensitivity analyses limiting the analyses to traced patients and to registries with $<50 \%$ LTFU in the first year.

\section{Results}

\section{Patient and Tumor Characteristics}

A total of 809 patients from 11 PBCRs were included; these patients represented one-fifth of all patients registered with BC during the study period (Table 2). Median age at diagnosis was 48 years. Approximately $16 \%$ of the cohort was aged $<35$ years at diagnosis, with $53 \%$ aged $<50$ years. Additional information on stage, therapy, or vital status was obtained for $63.9 \%$ (517 records) of patients using active methods (traced patients), and this proportion varied by registry (Table 2). Half of the registry records were traced to public hospitals, $14.7 \%$ were traced to private hospitals, and $35.2 \%$ could not be traced to a treatment facility (Table 3 ). We found that $65.0 \%$ of tumors were ductal carcinomas. Of the 809 patients, stage at diagnosis was known for $53.5 \%$ $(n=433$; supplemental eFigure 2). Of those with known stage, $20.8 \%$ had metastatic disease at time of diagnosis and $46.4 \%$ were diagnosed with stage III disease (ie, 67 . $2 \%$ in stages III and IV), with $<2 \%$ of patients diagnosed with stage I disease. When limited to the traced patients, stage at diagnosis was known for 405 patients, 320 of whom had nonmetastatic BC.

Regarding imagery for staging, imaging type was recorded in all registries apart from Addis Ababa. Less than $7 \%$ of patients had a record of using either a CT scan, an MRI, or bone scintigraphy for staging. Abdominal ultrasounds and chest and bone radiographs were the most commonly used means of screening for metastases. The HRS was recorded for $17.5 \%$ of all women and for $27.5 \%$ of traced patients.

\section{Therapy Characteristics}

\section{Therapy Received and Guideline Adherence}

In the population-based cohort, there was no record of any CDT for $48.7 \%$ of patients $(12.6 \%$ of these patients were traced but without any therapy, and $36.1 \%$ of records were not traced) (Table 1). Patients from registries in regions with medium HDI (Eldoret, Nairobi, and Namibia) had better access to therapy and/or records of therapy compared with those from registries in regions with low 


\begin{tabular}{|c|c|c|c|c|c|c|}
\hline & \multirow[b]{2}{*}{$\begin{array}{l}\text { Population-Based Cohort } \\
\text { n (\%) }\end{array}$} & \multicolumn{5}{|c|}{ Traced Cohort $(n=517)$} \\
\hline & & n (\%) & $\begin{array}{c}\text { Early-Stage } \mathrm{BC}^{\mathrm{a}} \\
\%\end{array}$ & $\begin{array}{l}\text { Locally Advanced } \mathbf{B C}^{\mathbf{b}} \\
\%\end{array}$ & $\begin{array}{c}\text { Metastatic BC } \\
\%\end{array}$ & $\begin{array}{c}\text { Unknown Stage } \\
\%\end{array}$ \\
\hline Total, N & 809 & 517 & 163 & 153 & 85 & 112 \\
\hline \multicolumn{7}{|l|}{ Chemotherapy } \\
\hline $\begin{array}{l}\text { Anthracycline-based } \\
\text { regimen (without a taxane) }\end{array}$ & $149(18.4)$ & $149(28.8)$ & 36.8 & 26.8 & 27.1 & 21.4 \\
\hline $\begin{array}{l}\text { Anthracyclines and } \\
\text { taxanes }\end{array}$ & $94(11.6)$ & $94(18.2)$ & 18.4 & 25.5 & 18.8 & 8.0 \\
\hline Others & $41(5.1)$ & $41(7.9)$ & 6.1 & 4.6 & 10.6 & 12.5 \\
\hline $\mathrm{CMF}$ & $5(0.6)$ & $5(1.0)$ & 1.8 & 0.6 & 0.0 & 0.9 \\
\hline None recorded & $228(28.2)$ & $228(44.1)$ & 36.8 & 42.5 & 43.5 & 57.1 \\
\hline Not traced & $292(36.1)$ & - & - & - & - & - \\
\hline \multicolumn{7}{|l|}{ Neoadjuvant chemotherapy } \\
\hline Yes & $92(11.4)$ & $92(17.8)$ & 22.1 & 22.2 & 12.9 & 8.9 \\
\hline None recorded & $425(52.5)$ & $425(82.2)$ & 77.9 & 77.8 & 87.1 & 91.1 \\
\hline Not traced & $292(36.1)$ & - & - & - & - & - \\
\hline \multicolumn{7}{|l|}{ Surgery } \\
\hline Mastectomy & $277(34.2)$ & $277(53.6)$ & 66.3 & 57.5 & 37.6 & 42.0 \\
\hline Lumpectomy & $43(5.3)$ & $43(8.3)$ & 10.4 & 3.3 & 5.9 & 14.3 \\
\hline None recorded & $197(24.4)$ & $197(38.1)$ & 23.3 & 39.2 & 56.5 & 43.7 \\
\hline Not traced & $292(36.1)$ & - & - & - & - & - \\
\hline \multicolumn{7}{|l|}{ Radiotherapy } \\
\hline Yes & $135(16.7)$ & $135(26.1)$ & 28.8 & 30.1 & 23.5 & 19.6 \\
\hline None recorded & $382(47.2)$ & $382(73.9)$ & 71.2 & 69.9 & 76.5 & 80.4 \\
\hline Not traced & $292(36.1)$ & - & - & - & - & - \\
\hline \multicolumn{7}{|l|}{ Hormone therapy } \\
\hline Yes and HR+ & $74(9.3)$ & $74(14.3)$ & 22.7 & 13.7 & 7.1 & 8.9 \\
\hline Yes and HRS unknown & $70(8.6)$ & $70(13.5)$ & 15.3 & 13.1 & 14.1 & 11.6 \\
\hline Yes and HR- & $4(0.5)$ & $4(0.8)$ & 0.6 & 0.0 & 1.2 & 1.8 \\
\hline No and HR+ & $23(2.7)$ & $23(4.4)$ & 4.9 & 4.6 & 2.3 & 4.5 \\
\hline No and HR- & $41(5.1)$ & $41(7.9)$ & 8.6 & 8.5 & 12.9 & 2.7 \\
\hline No and HRS unknown & $305(37.7)$ & $305(59.0)$ & 47.9 & 60.1 & 62.4 & 70.5 \\
\hline Not traced & $292(36.1)$ & - & - & - & - & - \\
\hline
\end{tabular}

HDI (Figure 1). There was no statistical association between age at diagnosis and therapy receipt, although there were lower proportions of women who initiated adequate therapy among patients aged 20 to 34 years and $\geq 65$ years (supplemental eFigure 3 ).

When we limited the analyses to the traced cohort $(n=517)$, there was no record of any form of CDT for $19.7 \%$ of patients (Table 3). Of these traced patients, 104 (20.1\%) had recorded the diagnostic information (stage at diagnosis and HRS) necessary for assessing therapy according to the NCCN Harmonized Guidelines for SSA ${ }^{9}$ (supplemental eFigure 4); the main characteristic unknown was the HRS for $72.5 \%$ of traced patients. We also found that $40.5 \%$ of traced patients with early BC and $58.2 \%$ of traced patients with locally advanced $\mathrm{BC}$ received inadequate therapy with no curative potential or had no record of therapy (Table 1). In total, of all traced patients with curable BC, $50.9 \%$ had inadequate or no CDT.

\section{Surgery}

Surgery was the most available form of therapy, with a surgical intervention documented for $41 \%$ of all women and $64.2 \%$ of traced patients (Table 3 ). Of those who had surgery recorded, $86.6 \%$ had a mastectomy. However, the type of mastectomy (simple, modified 
Table 1. Therapy Characteristics for Patients With BC by Stage at Diagnosis (cont.)

\begin{tabular}{|c|c|c|c|c|c|c|}
\hline & \multirow[b]{2}{*}{$\begin{array}{c}\text { Population-Based Cohort } \\
\text { n (\%) }\end{array}$} & \multicolumn{5}{|c|}{ Traced Cohort $(n=517)$} \\
\hline & & n (\%) & $\begin{array}{c}\text { Early-Stage } \mathbf{B C}^{\mathbf{a}} \\
\%\end{array}$ & $\begin{array}{c}\text { Locally Advanced } \mathbf{B C}^{\mathbf{b}} \\
\%\end{array}$ & $\begin{array}{c}\text { Metastatic BC } \\
\%\end{array}$ & $\begin{array}{c}\text { Unknown Stage } \\
\%\end{array}$ \\
\hline \multicolumn{7}{|l|}{ Targeted therapy } \\
\hline Yes and HER2+ & $8(1)$ & $8(1.5)$ & 2.4 & 0.7 & 2.3 & 0.9 \\
\hline No and HER2+ & $35(4.3)$ & $35(6.8)$ & 11.7 & 3.9 & 9.4 & 1.8 \\
\hline No and HER2- & $87(10.7)$ & $87(16.8)$ & 20.9 & 19.6 & 7.1 & 14.3 \\
\hline Not traced & $292(36.1)$ & - & - & - & - & - \\
\hline \multicolumn{7}{|l|}{ All CDT received } \\
\hline $\begin{array}{l}\text { Surgery }+ \text { systemic } \\
\text { therapy } \pm \text { radiotherapy }\end{array}$ & $234(28.9)$ & $234(45.3)$ & 59.5 & 41.8 & 36.5 & 36.6 \\
\hline Not traced & $292(36.1)$ & - & - & - & - & - \\
\hline
\end{tabular}

Stages classified for therapy assessment following the NCCN Harmonized Guidelines for Sub-Saharan Africa for Breast Cancer ${ }^{9}$ recommendations. For 4 patients the stage at diagnosis was recorded as stage III, without additional details, and thus could not be dichotomized for this table and was not included.

Abbreviations: BC, breast cancer; CDT, cancer-directed therapy; CMF, cyclophosphamide/methotrexate/5-fluorouracil; HR, hormone receptor; HRS, hormone receptor status.

aStages I, II, T3N1M0.

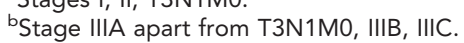

radical, or radical) was not always specified, and neither were details on surgical axillary node staging and dissection.

\section{Systemic Therapy}

We found that $55.9 \%$ of traced patients had a record of chemotherapy (Table 3). Of those, $51.6 \%$ had an anthracycline-based regimen, $32.5 \%$ had an anthracycline regimen with a taxane, and the others received different combinations of drugs.

In addition, $28.6 \%$ of traced patients received endocrine therapy (Table 3). In the traced cohort, 13.5\% of patients with tumors of unknown receptor status received endocrine therapy (Table 1 ). However, $4.4 \%$ of patients who had hormone receptor-positive disease had no record of receiving endocrine therapy. More patients diagnosed at early stages of disease had a record of receiving endocrine therapy (Table 1).

\section{Radiotherapy}

Approximately 1 in 4 traced patients received RT as part of their treatment regimen (Table 1). The proportion of patients who received RT varied by registry.

\section{Targeted Therapy}

Of traced patients, 35 (6.8\%) who had HER2-positive disease received no therapy with monoclonal antibodies, such as trastuzumab (Table 1). Use of trastuzumab was recorded for 8 patients in the entire cohort, 5 of them from Namibia.

\section{Long-Term Follow-Up}

LTFU was highest in the first year after diagnosis (supplemental eTable 1), and the proportion varied by registry. Namibia had the lowest fraction of patients with LTFU after diagnosis. Median follow-up time ranged from $<1$ year in Brazzaville, Bulawayo, and Cotonou to almost 5 years in Namibia. LTFU was not differential by age or stage at diagnosis among patients with a known stage. However, for patients without stage recorded, there was a more than 2 -fold increased risk of LTFU compared with patients diagnosed at an early stage.

\section{Survival}

The overall observed survival in this cohort was $84.0 \%$ (95\% CI, 80.5\%-86.9\%) at year 1, 58.9\% (95\% CI, $54.0 \%-63.5 \%)$ at year 3, and $47.2 \%$ (95\% CI, $41.1 \%-53.1 \%$ ) at year 5 (Figure 2). Patients with curable $\mathrm{BC}$ who received adequate therapy had better overall survival compared with those who received inadequate or no therapy (Figure 2). Figure 2 also shows overall survival for patients with metastatic disease, showing the poorest survival rates irrespective of the therapy received. 
Table 2. Population-Based Registries Included in the Study

\begin{tabular}{|c|c|c|c|c|c|c|c|c|}
\hline Registry & $\begin{array}{c}\text { Country-Level HDI } \\
2015\end{array}$ & $\begin{array}{l}\text { Period of } \\
\text { Diagnosis }\end{array}$ & $\begin{array}{c}\text { Patients With } \\
\text { BC During } \\
\text { Study Period } \\
\text { n }\end{array}$ & $\begin{array}{l}\text { DCO During } \\
\text { Study Period } \\
\text { Excluded } \\
\text { n (\%) }\end{array}$ & $\begin{array}{c}\text { Population-Based } \\
\text { Cohort } \\
n\end{array}$ & $\begin{array}{l}\text { Sampling } \\
\text { Fraction }\end{array}$ & $\begin{array}{c}\text { Traced } \\
\text { Cohort }^{b} \\
\text { n (\%) }\end{array}$ & $\begin{array}{c}\text { Included } \\
\text { for } \\
\text { Survival } \\
\text { Analyses } \\
\text { n (\%) }\end{array}$ \\
\hline $\begin{array}{l}\text { Abidjan, Cote } \\
\text { d'Ivoire }\end{array}$ & Low & 2012-2013 & 531 & $23(4.3)$ & 66 & $12.4 \%$ & $50(75.8)$ & $53(80.3)$ \\
\hline $\begin{array}{l}\text { Addis Ababa, } \\
\text { Ethiopia }\end{array}$ & Low & 2012 & 437 & $0(0.0)$ & 114 & $26.1 \%$ & $51(44.7)$ & 93 (81.6) \\
\hline Bamako, Mali & Low & 2012-2013 & 639 & $5(0.8)$ & 90 & $14.1 \%$ & $48(53.3)$ & $47(52.2)$ \\
\hline $\begin{array}{l}\text { Brazzaville, } \\
\text { Congo }\end{array}$ & Low & 2012-2013 & 212 & $0(0.0)$ & 75 & $35.4 \%$ & $19(25.3)$ & 75 (100) \\
\hline $\begin{array}{l}\text { Bulawayo, } \\
\text { Zimbabwe }\end{array}$ & Low & 2012-2013 & 167 & $16(9.6)$ & 56 & $33.5 \%$ & $35(62.5)$ & $53(94.6)$ \\
\hline $\begin{array}{l}\text { Cotonou, } \\
\text { Benin }\end{array}$ & Low & 2013-2014 & 132 & $0(0.0)$ & 92 & $69.7 \%$ & $85(92.4)$ & $92(100)$ \\
\hline $\begin{array}{l}\text { Eldoret, } \\
\text { Kenya }\end{array}$ & Medium & 2009-2014 & 379 & $17(4.5)$ & 81 & $21.4 \%$ & $62(76.5)$ & 69 (85.2) \\
\hline $\begin{array}{l}\text { Kampala, } \\
\text { Uganda }\end{array}$ & Low & 2012-2013 & 283 & $8(2.8)$ & 58 & $20.5 \%$ & $35(60.3)$ & $41(70.7)$ \\
\hline $\begin{array}{l}\text { Maputo, } \\
\text { Mozambique }\end{array}$ & Low & 2014-2015 & 81 & $14(17.8)$ & 43 & $53.1 \%$ & $34(79.1)$ & $41(95.4)$ \\
\hline $\begin{array}{l}\text { Nairobi, } \\
\text { Kenya }\end{array}$ & Medium & 2012-2013 & 722 & $38(5.3)$ & 57 & $7.9 \%$ & 37 (64.9) & 55 (96.5) \\
\hline Namibia & Medium & 2012-2013 & 454 & $0(0.0)$ & 77 & $17.0 \%$ & $61(79.2)$ & $64(83.1)$ \\
\hline Total & & 2009-2015 & 4,037 & $121(3.0)$ & 809 & $20.0 \%$ & $517(63.9)$ & $684(84.6)$ \\
\hline
\end{tabular}

Abbreviations: BC, breast cancer; DCO, death certificate-only patients; HDI, Human Development Index.

${ }^{b}$ Additional data on diagnostics, therapy, and/or outcome revealed after active record-finding.

\section{Excess Mortality From Nonmetastatic BC}

We assessed the excess mortality rate ratio among women with nonmetastatic disease and with at least 30 days of follow-up. Age at diagnosis was not an independent prognostic factor after adjusting for the effects of stage, tumor grade, therapy, and registry country-level HDI $(P=.389)$. Being diagnosed with stage III BC compared with stages I and II BC was associated with a more than 3 -fold increased risk of death rate ratio (risk ratio [RR], 3.83; 95\% CI, 1.81-6.11; Figure 3). Patients who received inadequate or no therapy had more than double the risk of death compared with patients who initiated adequate therapy (Figure 3). Mortality risk did not differ by registry HDI (low vs medium).

Concerning specific therapy modalities (supplemental eFigure 5), not receiving oncologic surgery was associated with an increased risk of death compared with receiving surgery (RR, 1.67; 95\% CI, 1.06-2.65). Having suboptimal chemotherapy was associated with a more than 2-fold increased risk of death (RR, 2.38; 95\% CI, 1.24-4.57) compared with receiving $>85 \%$ of the prescribed chemotherapy regimen. Receipt of RT was not associated with a difference in mortality risk. Nonreceipt of endocrine therapy was associated with an approximately 3 -fold increased mortality risk (RR, 3.11; 95\% CI, 1.50-6.10). When we conducted sensitivity analyses, limiting the analyses just to traced patients and excluding Brazzaville (with $>50 \%$ LTFU at year 1), these observed associations remained unchanged.

\section{Discussion}

Main Findings in the Context of Previous Studies

$\mathrm{BC}$ is a curable disease when diagnosed early and treated according to guidelines. This study shows the tenuous situation of women with BC in SSA; most patients are diagnosed at an advanced stage and only a small proportion receive guideline-concordant therapy. Of 809 women from 11 PBCRs in 10 countries, we traced 517 patient records $(63.9 \%)$ and obtained detailed therapy information. Two in 3 patients $(67.2 \%)$ with known stage were diagnosed with stage III or IV BC; however, given the limited access to advanced radiologic tools such as CT scans, bone scintigrams, and MRIs, this proportion may be even higher. Of traced patients with curable BC, 50.9\% received inadequate or no CDT. Of all traced patients, the HRS was known for $27.5 \%$ of patients, making the use of current therapy guidelines challenging. The proportion of patients who received adequate therapy varied by registry (with patients in relatively richer countries receiving 


\section{Table 3. Cohort Characteristics}

\begin{tabular}{|c|c|c|}
\hline Characteristic & $\begin{array}{c}\text { Population-Based } \\
\text { Cohort } \\
\text { n (\%) }\end{array}$ & $\begin{array}{c}\text { Traced Cohort } \\
\text { n (\%) }\end{array}$ \\
\hline Total, N & 809 & 517 \\
\hline \multicolumn{3}{|l|}{ Age at diagnosis } \\
\hline $20-34$ y & $129(15.9)$ & $78(15.1)$ \\
\hline $35-49$ y & $300(37.1)$ & $196(37.9)$ \\
\hline $50-64$ y & $273(33.8)$ & $175(33.9)$ \\
\hline$\geq 65 y$ & $107(13.2)$ & $68(13.1)$ \\
\hline \multicolumn{3}{|l|}{ Additional information found } \\
\hline Yes (traced cohort) & $517(63.8)$ & - \\
\hline $\begin{array}{l}\text { No additional information } \\
\text { except registry data }\end{array}$ & $292(36.2)$ & - \\
\hline \multicolumn{3}{|l|}{ Hospital type } \\
\hline Public hospital & $405(50.1)$ & $385(74.5)$ \\
\hline Private hospital & $119(14.7)$ & $94(18.2)$ \\
\hline Unknown & $285(35.2)$ & $38(7.3)$ \\
\hline \multicolumn{3}{|l|}{ ECOG performance status } \\
\hline $0 / 1$ & $144(17.8)$ & $144(27.8)$ \\
\hline 2 & $31(3.8)$ & $31(6.0)$ \\
\hline 3 & $19(2.4)$ & $19(3.7)$ \\
\hline 4 & $4(0.5)$ & $4(0.8)$ \\
\hline Unknown & $611(75.5)$ & $319(61.7)$ \\
\hline \multicolumn{3}{|l|}{ Tumor size } \\
\hline$\leq 5 \mathrm{~cm}(\mathrm{~T} 1-\mathrm{T} 2)$ & $120(14.8)$ & $110(21.3)$ \\
\hline$>5 \mathrm{~cm}(\mathrm{~T} 3-\mathrm{T} 4)$ & $257(31.8)$ & $252(48.7)$ \\
\hline Unknown & $432(53.4)$ & $155(30.0)$ \\
\hline \multicolumn{3}{|l|}{ Nodal involvement } \\
\hline Present & $89(11.0)$ & $85(16.4)$ \\
\hline Absent & $256(31.6)$ & $248(48.0)$ \\
\hline Unknown & $464(57.4)$ & $184(35.6)$ \\
\hline \multicolumn{3}{|l|}{ TNM stage } \\
\hline I & $12(1.5)$ & $10(1.9)$ \\
\hline II & $130(16.1)$ & $119(23.0)$ \\
\hline III & $201(24.8)$ & $191(36.9)$ \\
\hline IV & $90(11.1)$ & 85 (16.4) \\
\hline Unknown & $376(46.5)$ & $112(21.7)$ \\
\hline \multicolumn{3}{|l|}{ Tumor grade } \\
\hline 1 & $32(4.0)$ & $32(6.2)$ \\
\hline 2 & $124(15.3)$ & $124(24.0)$ \\
\hline 3 & 85 (10.5) & 85 (16.4) \\
\hline Unknown & $568(70.2)$ & $276(53.4)$ \\
\hline \multicolumn{3}{|l|}{ HRS } \\
\hline ER/PR-negative & $45(5.5)$ & $45(8.7)$ \\
\hline ER/PR-positive & $97(12)$ & $97(18.8)$ \\
\hline Unknown & $667(82.5)$ & 375 (72.5) \\
\hline
\end{tabular}

(continued)

\begin{tabular}{|c|c|c|}
\hline Characteristic & $\begin{array}{c}\text { Population-Based } \\
\text { Cohort } \\
n(\%)\end{array}$ & $\begin{array}{c}\text { Traced Cohort } \\
\text { n (\%) }\end{array}$ \\
\hline \multicolumn{3}{|l|}{ HER2 status } \\
\hline Positive & $43(5.3)$ & $43(8.3)$ \\
\hline Negative & $87(10.8)$ & $87(16.8)$ \\
\hline Unknown & $679(83.9)$ & 387 (74.9) \\
\hline \multicolumn{3}{|l|}{ Therapy received } \\
\hline Surgery & 332 (41.0) & $332(64.2)$ \\
\hline Chemotherapy & $289(35.7)$ & $289(55.9)$ \\
\hline Radiotherapy & 135 (16.7) & $135(26.1)$ \\
\hline Endocrine therapy & $148(18.3)$ & $148(28.6)$ \\
\hline None recorded & $102(12.6)$ & $102(19.7)$ \\
\hline Unknown & $292(36.1)$ & - \\
\hline
\end{tabular}

Abbreviations: ER, estrogen receptor; HRS, hormone receptor status; PR, progesterone receptor.

more comprehensive therapy), accounting for some of the differences in survival observed across different SSA countries.

Adequate BC therapy requires a multidisciplinary approach and is resource-intensive. Many of the women in our cohort received only fragmented care or none at all. Limited access to these main forms of therapy has been described for SSA, ${ }^{12}$ linked to both geographic and financial inaccessibility, with most women having to pay out-of-pocket for healthcare. ${ }^{13,14}$ In this study, surgery was the most available therapy option, with $64.2 \%$ of women in the traced cohort having a record of surgery. Still, many women never received surgery because of either

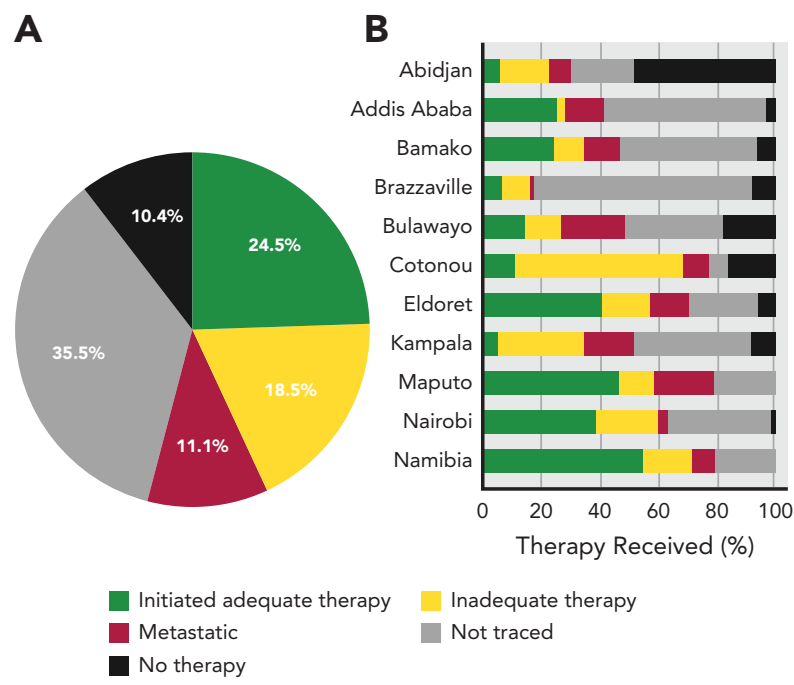

Figure 1. Recorded therapy received by patients (A) in the population-based cohort $(n=809)$ and $(B)$ by registry area. 
A

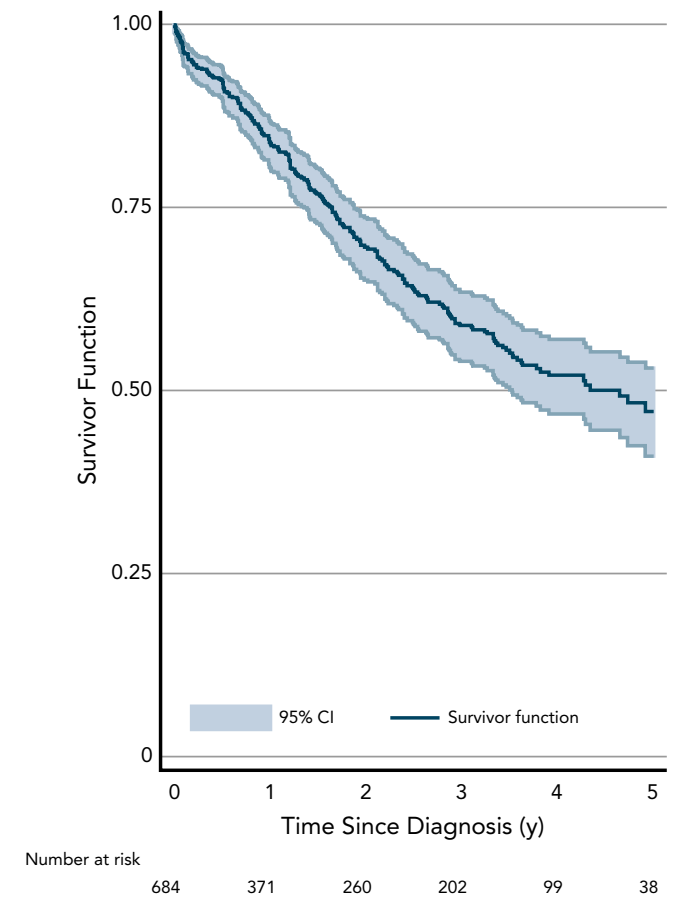

B

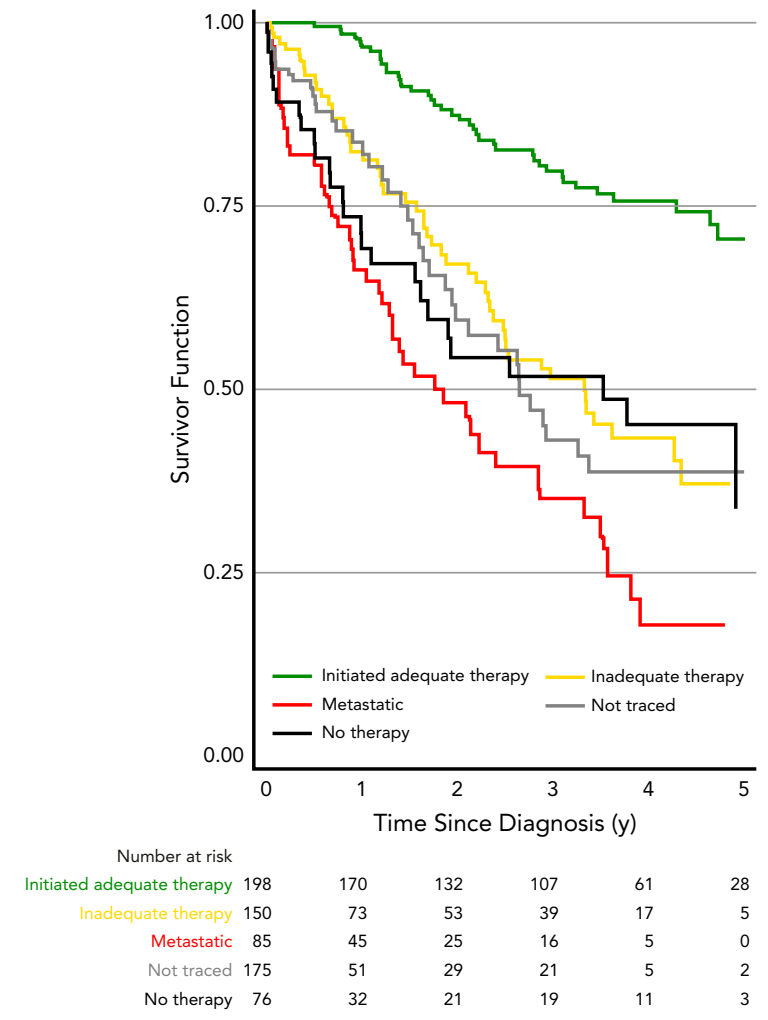

Figure 2. Overall survival (A) in the population-based cohort and (B) by therapy received.

inoperable or stage IV disease, fear of disfigurement, lack of access to surgery, or options to use neoadjuvant chemotherapy. ${ }^{15}$ Initiatives to task-share surgical BC care in primary and secondary healthcare facilities (vs tertiary healthcare facilities) have been proposed to increase the accessibility of this essential intervention. ${ }^{16}$ The main type of surgery received was mastectomy, in line with recommendations for areas with limited access to RT. However, in terms of emotional and social coping, mastectomy is often difficult for patients, ${ }^{17}$ particularly young patients in the absence of counseling and with limited access to reconstructive surgery.

Systemic treatment of $\mathrm{BC}$ requires specialists. In a review of the oncologic workforce worldwide, it was estimated that in 25 of the 32 African countries represented, there was approximately 1 clinical oncologist per 1,000 incident patients. ${ }^{18}$ Of the countries included in this study, this number ranged from 1 clinical oncologist per 325 incident patients in Namibia to 1 per 10,167 incident patients in Ethiopia. In the United States, there is approximately 1 clinical oncologist per 137 incident patients. Chemotherapy is not readily available; of traced patients, $>40 \%$ of those with locally advanced cancer received no chemotherapy. This led to decreased survival; receiving suboptimal or no chemotherapy was associated with a poorer prognosis compared with completing the treatment regimen. These results must be interpreted with care because reverse causation is possible (see "Limitations").

Concerning RT, in 2010, it was estimated that in Africa there was $<1$ RT machine per million people, compared with almost 15 RT machines per million people in North America. ${ }^{19}$ Even within Africa, there are significant disparities in access: $60 \%$ of RT facilities are found in southern and northern Africa, with 23 countries without any RT facilities. ${ }^{19}$ The NCCN Harmonized Guidelines for SSA ${ }^{9}$ acknowledge this deficit in the therapy recommendations, and provide therapy guidelines that could be followed in the absence of RT facilities. Most of the patients in our cohort were candidates for RT, but only 1 in 4 traced patients received it. Of the 10 countries included, RT was available in only 5 of these countries at the time of the study: Ethiopia, Kenya, Namibia, Uganda, and Zimbabwe. A few patients from registries without in-country RT facilities had traveled abroad to receive the treatment. RT is necessary not only for curative purposes but also for palliation; approximately $70 \%$ of patients present at advanced stages with limited access to opioid analgesics in the region. ${ }^{20}{ }^{21}$ RT further decreases the risk of locoregional recurrence and mortality for women with stage III BC. ${ }^{22}$ 


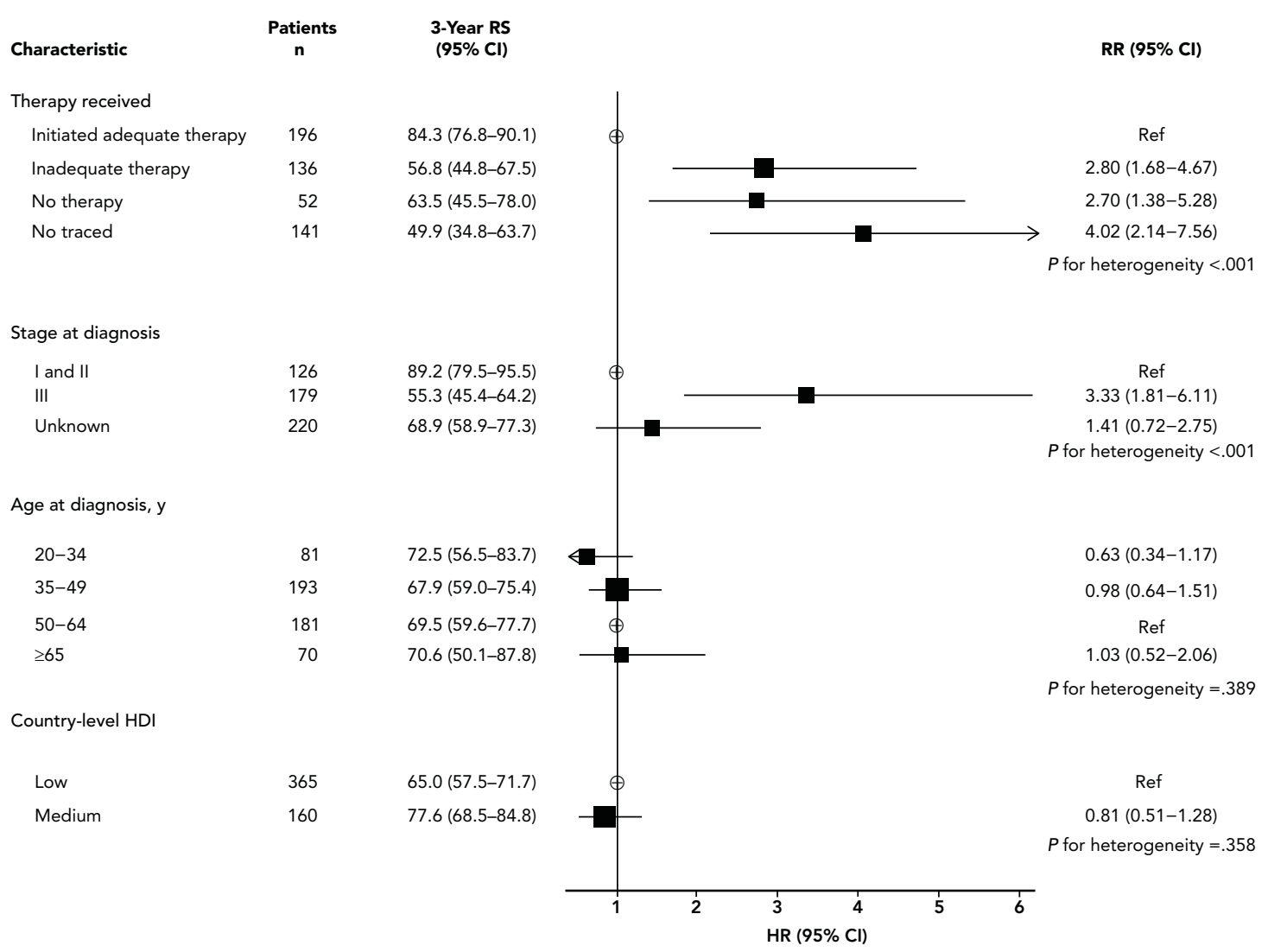

Figure 3. Three-year RS and excess risk of death from breast cancer among women in the population-based cohort without known metastases and with at least 30 days of follow-up $(n=525)$ adjusted for therapy, stage, age, and country-level HDI.

Abbreviations: HDI, Human Development Index; HR, hazard ratio; RR, risk ratio; RS, relative survival.

Endocrine treatment is effective for hormone receptor-positive tumors, has few adverse effects, and could be available at comparatively low costs. However, the HRS was unknown for $72.5 \%$ of the traced patients. In some of the registry areas included in this study, there was only 1 (Addis Ababa, Cotonou) or no (Bamako) laboratory with immunohistochemistry facilities for HRS testing. ${ }^{23}$ The NCCN Harmonized Guidelines for SSA ${ }^{9}$ present the standard-of-care situation with the availability of HRS and do not make recommendations for treatment when the HRS is unknown. Previous recommendations have suggested giving endocrine therapy to women with locally advanced BC even with unknown HRS. ${ }^{24}$ Patients who did not initiate endocrine therapy in this study had a more than 2-fold increased hazard of death compared with those who did initiate endocrine therapy, after accounting for the effect of stage and other therapy modalities.

Access to these different treatment modalities varied by registry, as seen in Figure 1. Of the registries included in our study, the Namibian national healthcare system provides free therapy for patients with cancer, ${ }^{6}$ including transport service to and from remote areas. This level of access seemed to be reflected in physicians actually seeing the highest proportion of patients who initiated adequate therapy (Figure 1). Such government policies may serve as an example for best practices in access to "oncology health service for all" for patients who most likely otherwise fall out of the system. There was less comprehensive or nonexistent health coverage at public hospitals for all the other registries at the time of this study, leading to high disparities within countries. Even where government subsidies exist, medication stock-outs, indirect medical costs, and breakdowns of RT machines make completing therapy challenging, ${ }^{25}$ as do the indirect costs of transport, accommodation, and supportive therapy.

A recent hospital-based study that prospectively included 2,228 patients with BC presented the survival effects of different risk factors, including the impact of late stage, lack of treatment, tumor biology, positive HIV status, and age. Notably, little education, poor awareness, rural residence, and lower socioeconomic status were associated with poorer survival outcomes. The authors showed that survival improvement (up to $22 \%$ ) was achievable through downstaging and the availability of basic treatment. Patients from Namibia showed much better outcomes compared with patients from South Africa, 
Uganda, Zambia, and Nigeria. ${ }^{26}$ This better 3-year survival for patients from Namibia is similar to findings from the population-based registries included in the current study. ${ }^{5}$

Thus, although therapy guidelines are useful tools to help ensure good-quality cancer care in low- and middleincome countries, patients in resource-poor settings still face challenges such as differences in access to quality cancer diagnostics and care, especially in settings where treatment costs are not subsidized.

\section{Limitations}

A limitation of our study is its retrospective nature, which is prone to biases, and the difficulties of obtaining complete treatment data retrospectively in these settings. In addition, we could not measure and control for all potential confounders. We did not adjust for the time until onset of therapy (delay) in the final model because it was not consistently recorded for many patients. We could not measure and adjust for other factors that could influence survival, such as adherence to endocrine therapy and RT, comorbidities, molecular tumor type, and nutritional status, along with psychosocial factors influencing patient acceptance of diagnosis and therapy. In addition, relatively large proportions of patients were lost to follow-up in the first year after diagnosis, despite the active methods used to ascertain their vital status, which could result in an overestimation of survival. These high proportions of LTFU were linked to a lack of plans for patient navigation and retention and equally poor recordkeeping in some of these health systems. There could equally be the risk of immortal time bias in some of the associations seen ${ }^{27}$; for instance, only women who survived long enough postsurgery could be prescribed systemic therapy. We tried to minimize this bias by excluding patients who died or were lost to follow-up within the first 30 days. A correlation between the severity of disease and choice of therapy or "confounding by indication" is a challenge in observational studies. ${ }^{28}$ The relative contribution of these different therapy modalities to survival outcomes would ideally be disentangled with the use of randomized controlled trials. However, randomized controlled trials to measure outcomes in relation to the basic therapy options we investigated are not ethically feasible-thus observation and sensible deduction are the only courses available, with very careful interpretation of any observed associations between prognostic factors and outcome.

The records of $36.1 \%$ of patients registered in the PBCRs could not be traced to a treatment facility. We assumed that many of these patients never actually initiated therapy, and therefore never had a clinical treatment file opened after the pathology report. However, inadequate paper-based record systems and the absence of technological frameworks to facilitate record linkage could be a reason for the lack of tracing.
Despite these limitations, this study provides a clearer picture of the actual therapy received by a random sample of women with BC in SSA at the population level, not simply among patients attending reference treatment centers. We included women from both public and private institutions from 10 countries and patients with no record of therapy, reflecting different pathways to care, thus providing a deeper insight into the therapy routinely received by women in SSA and how this influences their survival.

\section{Conclusions}

In SSA, most women are diagnosed with BC before 50 years of age, and have a $<50 \%$ chance of surviving 5 years after diagnosis. Many patients do not have access to adequate therapy or-even worse-receive inappropriate cancer care with limited survival benefits and potential adverse effects. The resulting impact of lost health and productivity cannot be overemphasized. Improving access to adequate cancer therapy to prolong life, prevent recurrence, reduce stigma, and alleviate pain is necessary. Adequate therapy requires awareness of therapy options, willingness to receive conventional medical therapy, availability of these resources locally, and the means to finance healthcare. Our study sites are almost all large urban centers; access to care would even be poorer in rural settings, with more limited awareness, fewer health facilities, longer travel time to access care, and even lower ability to pay for healthcare. Despite these conditions, there are approaches available to improve access to adequate care in SSA.

Governments and nongovernmental organizations should keep working toward improving the infrastructure, such as availability of HRS testing and cancer care facilities locally based on the strategies outlined in the NCCN Harmonized Guidelines for $\mathrm{SSA}^{9}$ so that guideline-concordant treatments can effectively be administered. It is imperative to improve recordkeeping and data management facilities to support patient monitoring and retention and to facilitate cancer surveillance and implementation research. The inherent challenge remains financing healthcare in low-resource settings. In the meantime, we must keep emphasizing improving awareness and facilitating access to quality care to help downstage BC and improve survival outcomes. A greater focus on systemic and systematic building of infrastructure is needed to overcome the huge discrepancy between well-known effective cancer care and what is actually received on the ground.

\section{Acknowledgments}

We are grateful to the staff of all the population-based registries of the African Cancer Registry Network for data collection and patient follow-up.

Submitted August 6, 2020; final revision received January 20, 2021; accepted for publication January 20, 2021. Published online December 29, 2021. 
Author contributions: Study concept and design: Joko-Fru, Jemal, Parkin, Kantelhardt. Data acquisition, analysis, or interpretation: All authors. Statistical analysis: Joko-Fru, Kantelhardt. Administrative, technical, or material support: Liu, Jemal, Parkin, Kantelhardt. Study supervision: Jemal, Parkin, Kantelhardt. Writing - original draft: Joko-Fru, Jemal, Parkin, Kantelhardt. Writing - review and editing: Joko-Fru, Griesel, Mezger, Hämmerl, Seraphin, Feuchtner, Nsonde Malanda, Gnangnon, Lorenzoni, Thomssen, McGale, Jemal, Parkin, Kantelhardt. Full access to all data in the study and responsibility for the integrity of data and accuracy of data analysis: Joko-Fru, Kantelhardt.

Disclosures: The authors have disclosed that they have not received any financial consideration from any person or organization to support the preparation, analysis, results, or discussion of this article.

Funding: Dr. Joko-Fru was the recipient of a 3-month Halle-Oxford exchange fellowship grant within EU/ESF-funded research for the International Research Network Biology of Disease and Molecular Medicine (ZS/2016/08/80642) from Martin-Luther-University HalleWittenberg and is a Commonwealth Scholar whose DPhil at the
University of Oxford is funded by the UK government. Dr. Mezger was supported by the German Academic Exchange Service (DAAD), financed by the Federal Ministry of Education and Research and the Roland Ernst Stiftung für Gesundheitswesen. Dr. Hämmerl was supported by Bischöfliche Studienförderung Cusanuswerk through her regula scholarship. Dr. Seraphin was supported by Studienstiftung des Deutschen Volkes e.V. through his regular scholarship. Dr. Feuchtner was given a doctorate stipend by Bayer Foundation. Dr. Kantelhardt was supported by intramural funding from the research department of the American Cancer Society (contract number 43359).

Disclaimer: The funders were not involved in the study design, data collection, analyses, interpretation, or write-up of the manuscript. The corresponding author had full access to the data and had the final responsibility for manuscript submission.

Correspondence: Eva J. Kantelhardt, MD, Institute of Medical Epidemiology, Biostatistics and Informatics, Martin-Luther-University Halle-Wittenberg, Magdeburger Straße 8 06112, Halle (Saale), Germany.

Email: eva.kantelhardt@uk-halle.de

\section{References}

1. International Agency for Research on Cancer, World Health Organization. The Global Cancer Observatory. Population fact sheet: Africa. Accessed January 25, 2021. Available at: https://gco.iarc.fr/today/data/factsheets/ populations/903-africa-fact-sheets.pdf

2. Jedy-Agba E, McCormack V, Adebamowo C, et al. Stage at diagnosis of breast cancer in sub-Saharan Africa: a systematic review and meta-analysis. Lancet Glob Health 2016;4:e923-935.

3. Sankaranarayanan $\mathrm{R}$, Swaminathan $\mathrm{R}$, Brenner $\mathrm{H}$, et al. Cancer survival in Africa, Asia, and Central America: a population-based study. Lancet Oncol 2010;11:165-173.

4. Allemani C, Matsuda T, Di Carlo V, et al. Global surveillance of trends in cancer survival 2000-14 (CONCORD-3): analysis of individual records for 37513025 patients diagnosed with one of 18 cancers from 322 populationbased registries in 71 countries. Lancet 2018;391:1023-1075.

5. Joko-Fru WY, Miranda-Filho A, Soerjomataram I, et al. Breast cancer survival in sub-Saharan Africa by age, stage at diagnosis and human development index: a population-based registry study. Int J Cancer 2020;146:1208-1218.

6. Foerster M, Anderson BO, McKenzie F, et al. Inequities in breast cancer treatment in sub-Saharan Africa: findings from a prospective multi-country observational study. Breast Cancer Res 2019;21:93.

7. National Comprehensive Cancer Network. NCCN Harmonized Guidelines for Sub-Saharan Africa. Accessed January 25, 2021. To view the most recent version, visit NCCN.org

8. African Cancer Registry Network. About us. Accessed March 15, 2018 Available at: http://afcrn.org/about-us/20-afcrn

9. Gradishar WJ, Robert CH, Anderson BO, et al. NCCN Harmonized Guidelines for Sub-Saharan Africa for Breast Cancer. Version 2.2017 Accessed June 5, 2018. To view the most recent version, visit NCCN.org

10. Sobin LH, Gospodarowicz MK, Wittekind C, eds. TNM Classification of Malignant Tumors, 7th ed. Hoboken, NJ: Wiley; 2011.

11. Loibl S, Skacel T, Nekljudova V, et al. Evaluating the impact of Relative Total Dose Intensity (RTDI) on patients' short and long-term outcome in taxane- and anthracycline-based chemotherapy of metastatic breast cancer-a pooled analysis. BMC Cancer 2011;11:131.

12. Stefan DC. Cancer care in Africa: an overview of resources. J Glob Oncol 2015;1:30-36.

13. Knaul F, Horton $S$, Yerramilli $P$, et al. Financing cancer care in low-resource settings. In: Gelband H, Jha P. Sankaranarayanan R, et al, eds. Cancer: Disease Control Priorities, 3rd ed. Vol. 3. Washington, DC: The International Bank for Reconstruction and Development/The World Bank; 2015: Chapter 17.

14. Twahir M, Oyesegun RA, Yarney J, et al. Access to care and financial burden for patients with breast cancer in Ghana, Kenya, and Nigeria [abstract]. J Clin Oncol 2019;37(Suppl):Abstract 6562.
15. Sutter SA, Slinker A, Balumuka DD, et al. Surgical management of breast cancer in Africa: a continent-wide review of intervention practices, barriers to care, and adjuvant therapy. J Glob Oncol 2017;3:162-168.

16. Sullivan R, Alatise Ol, Anderson BO, et al. Global cancer surgery: delivering safe, affordable, and timely cancer surgery. Lancet Oncol 2015;16:1193_ 1224.

17. Tetteh DA, Faulkner SL. Sociocultural factors and breast cancer in subSaharan Africa: implications for diagnosis and management. Womens Health (Lond) 2016;12:147-156.

18. Mathew A. Global survey of clinical oncology workforce. J Glob Onco 2018;4:1-12.

19. Abdel-Wahab M, Bourque JM, Pynda Y, et al. Status of radiotherapy resources in Africa: an International Atomic Energy Agency analysis. Lancet Oncol 2013;14:e168-175.

20. World Health Organization. Ensuring balance in national policies on controlled substances: guidance for availability and accessibility of controlled medicines. Accessed January 26, 2021. Available at: https://apps.who.int/ iris/handle/10665/44519

21. Seya MJ, Gelders SFAM, Achara OU, et al. A first comparison between the consumption of and the need for opioid analgesics at country, regional, and global levels. J Pain Palliat Care Pharmacother 2011;25:6-18.

22. McGale P, Taylor C, Correa C, et al. Effect of radiotherapy after mastectomy and axillary surgery on 10-year recurrence and 20-year breast cancer mortality: meta-analysis of individual patient data for 8135 women in 22 randomised trials. Lancet 2014;383:2127-2135.

23. Ziegenhorn HV, Frie KG, Ekanem IO, et al. Breast cancer pathology services in sub-Saharan Africa: a survey within population-based cancer registries. BMC Health Serv Res 2020;20:912.

24. Carlson RW, Anderson BO, Chopra R, et al. Treatment of breast cancer in countries with limited resources. Breast J 2003;9(Suppl 2):S67-74.

25. Swanson M, Ueda S, Chen LM, et al. Evidence-based improvisation: facing the challenges of cervical cancer care in Uganda. Gynecol Oncol Rep 2018; 24:30-35.

26. McCormack $V$, McKenzie F, Foerster M, et al. Breast cancer survival and survival gap apportionment in sub-Saharan Africa (ABC-DO): a prospective cohort study. Lancet Glob Health 2020;8:e1203-1212.

27. Newman NB, Brett CL, Kluwe CA, et al. Immortal time bias in national cancer database studies. Int J Radiat Oncol Biol Phys 2020;106:5-12.

28. de Glas NA, Kiderlen M, de Craen AJM, et al. Assessing treatment effects in older breast cancer patients: systematic review of observational research methods. Cancer Treat Rev 2015:41:254-261. 
Supplemental online content for:

\section{Breast Cancer Diagnostics, Therapy, and Outcomes in Sub-Saharan Africa: A Population-Based Registry Study}

Walburga Yvonne Joko-Fru, MD, MSc; Mirko Griesel, MD; Nikolaus Christian Simon Mezger, MD; Lucia Hämmerl, MD; Tobias Paul Seraphin, MD; Jana Feuchtner, MD; Henry Wabinga, MD, MMed; Guy N'da, MD, MPH; Assefa Mathewos, MD; Bakarou Kamaté, MD; Judith Nsonde Malanda, MD; Freddy Houéhanou Rodrigue Gnangnon, MD, MPH; Gladys Chebet Chesumbai, BSc; Anne Korir, MD, MPH; Cesaltina Lorenzoni, MD, PhD; Annelle Zietsman, MBChB; Margaret Ziona Borok, MBChB; Biying Liu, MSc; Christoph Thomssen, MD; Paul McGale, PhD; Ahmedin Jemal, DVM, PhD; Donald Maxwell Parkin, MD, DSc; and Eva Johanna Kantelhardt, MD

J Natl Compr Canc Netw, doi: 10.6004/jnccn.2021.7011

eFigure 1: Data Management and Patient Flow-Chart for Study Inclusion

eFigure 2: Breast Cancer Stage Distribution at Diagnosis by Population-Based Cancer Registry eFigure 3: Therapy Receipt by Age at Diagnosis Among Women With Breast Cancer eFigure 4: Patient Cohorts Showing Use of at Least One Type of CDT, and OS by Therapy eFigure 5: 3-Year Relative Survival and Excess Risk of Death From Breast Cancer

eTable 1: Median Age at Diagnosis, Proportion of Deaths, and Loss to Follow-Up in First 3 Years After Diagnosis by Registry Index 


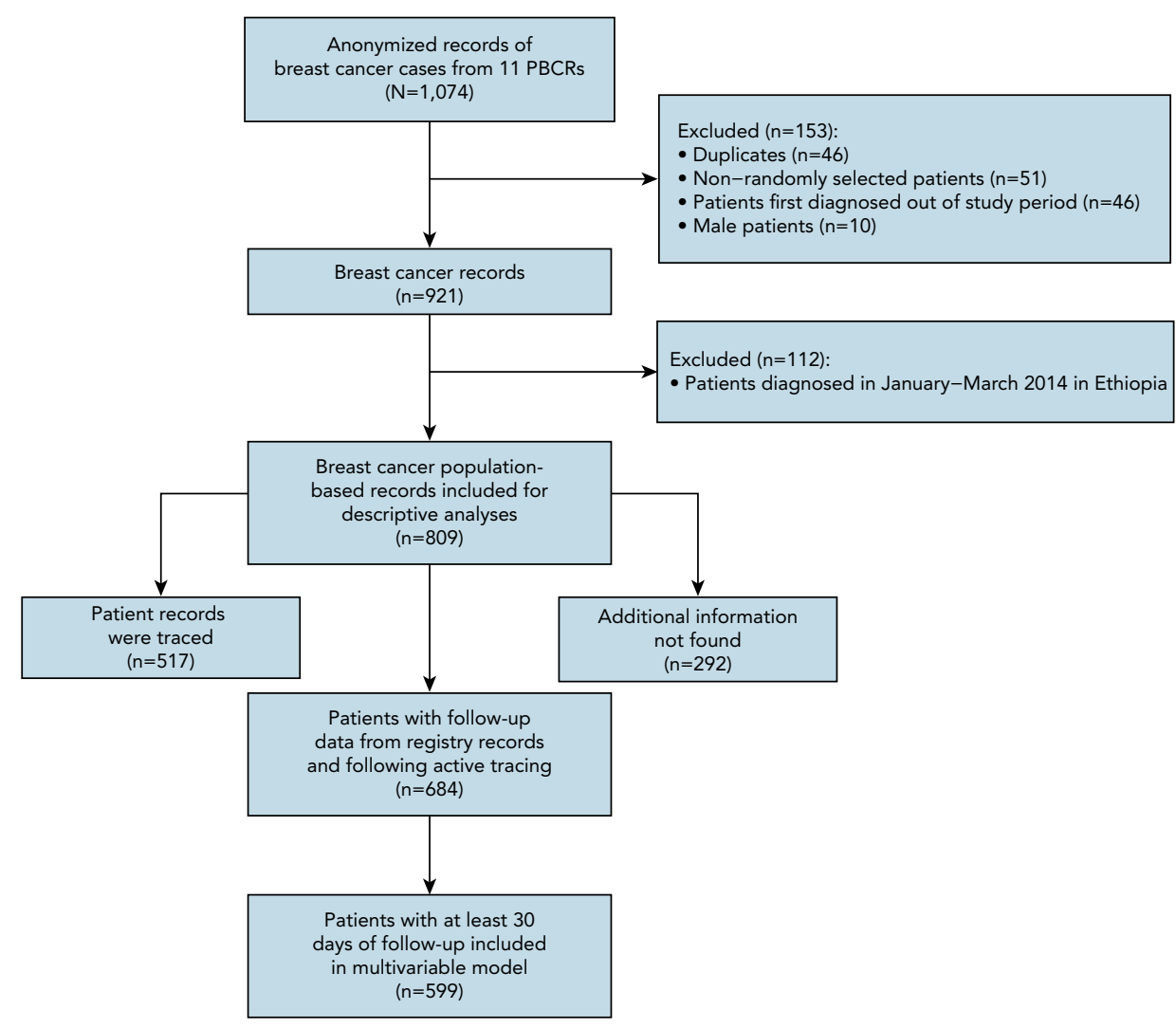

eFigure 1. Data management and patient flow-chart for study inclusion.

Note: The original sample included patients diagnosed from January to March 2012 and 2014 from Ethiopia (which was the first pilot site); however, to prevent an overweighting of any outcomes by patients from Ethiopia, we included only patients diagnosed in 2012.

Abbreviation: $\mathrm{PBCR}$, population-based cancer registry. 

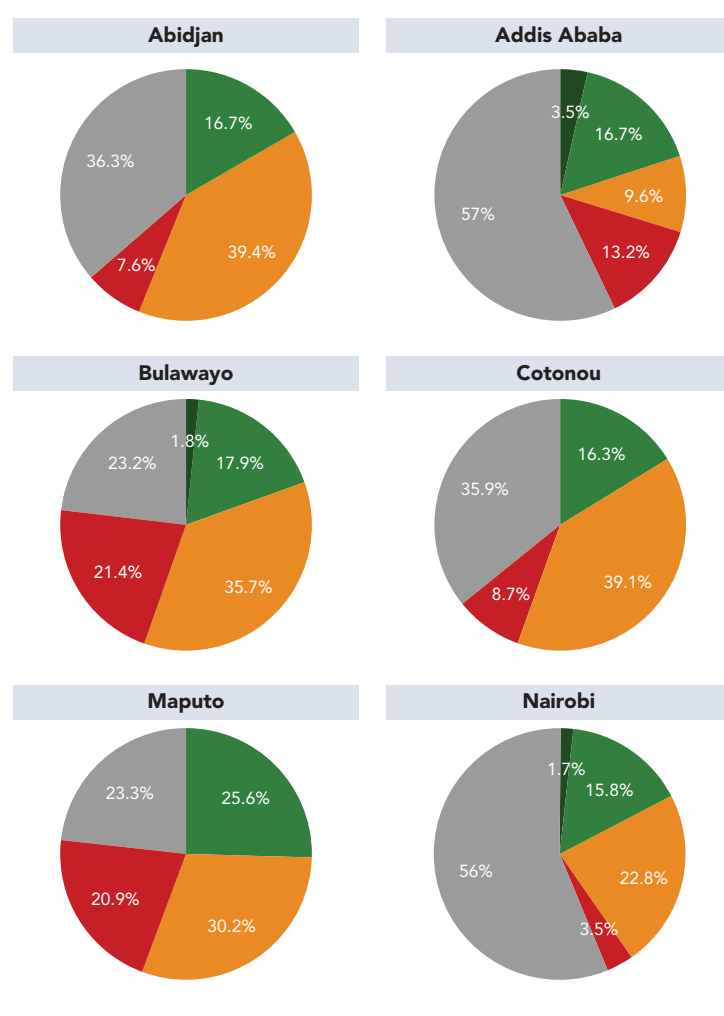

Stage I

Stage II

Stage III
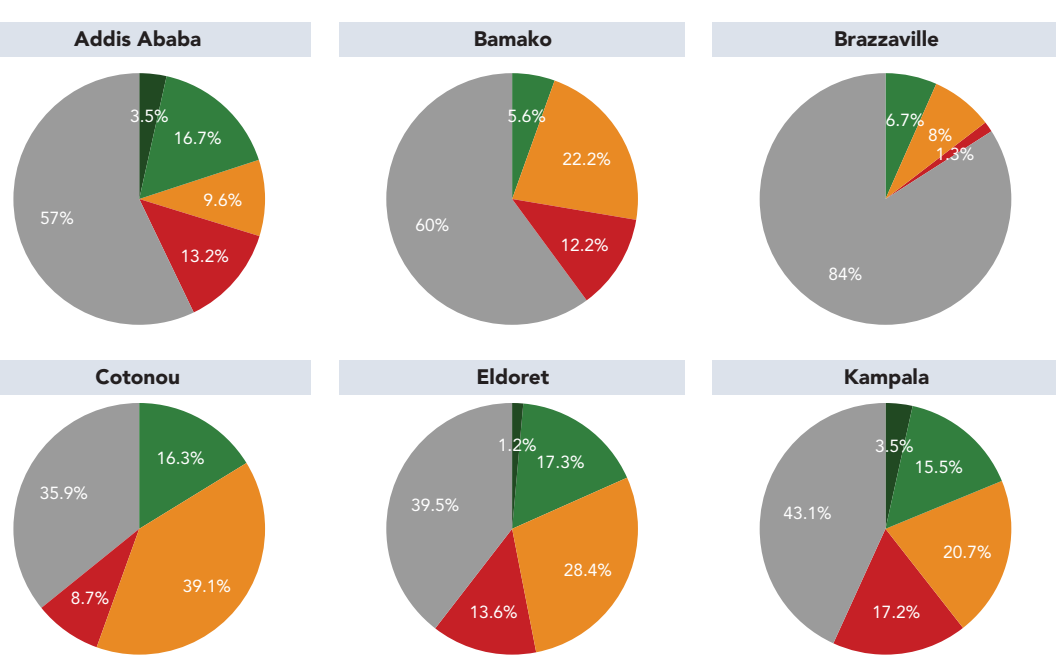

Namibia
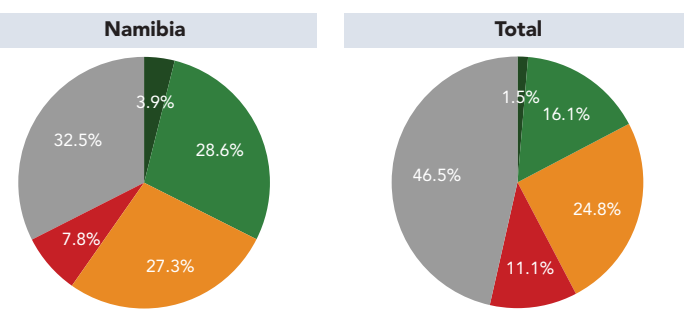

Stage IV

Unknown stage

eFigure 2. Breast cancer stage distribution at diagnosis by population-based cancer registry. 

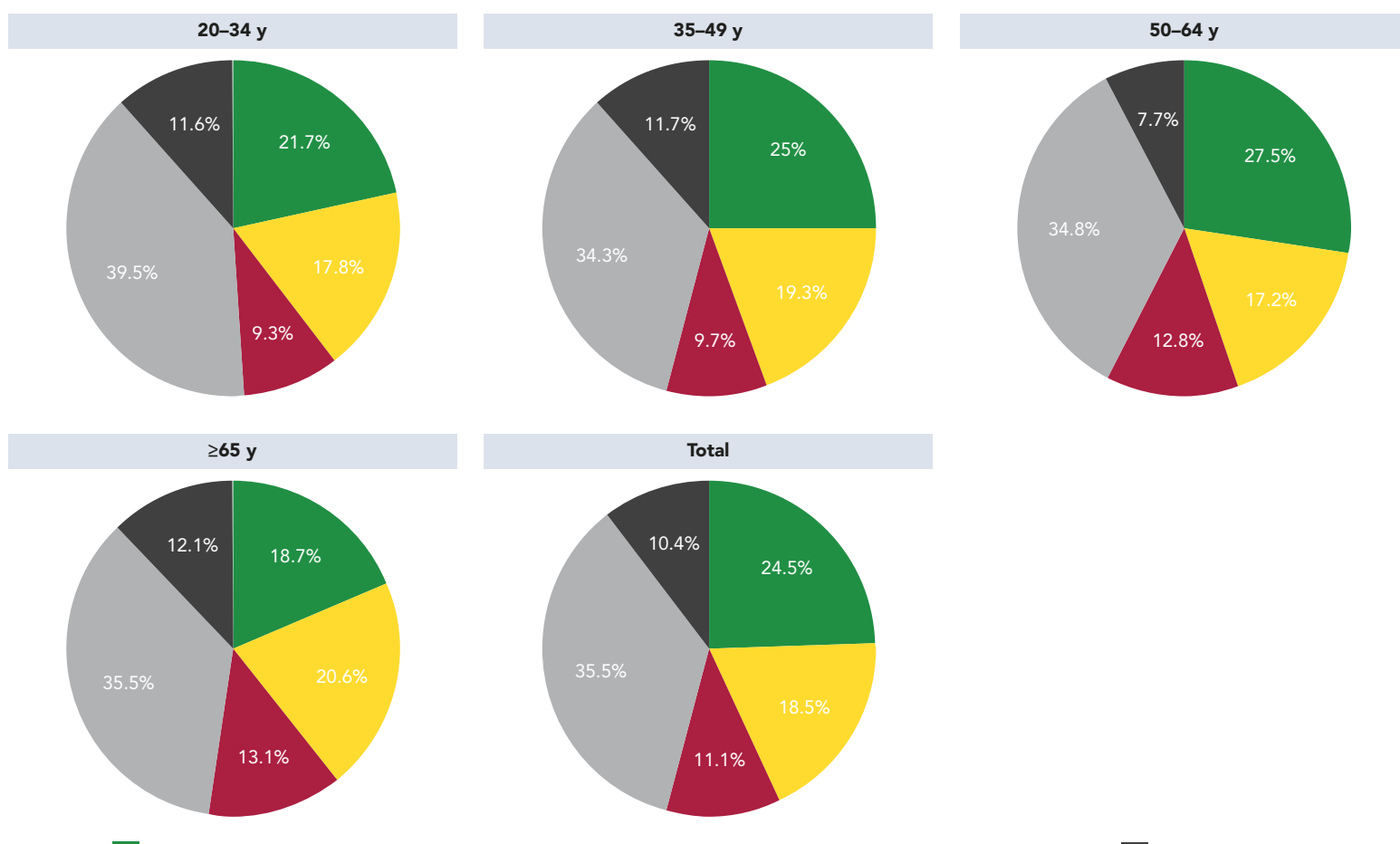

Initiated adequate therapy

Inadequate therapy

Metastatic

Not traced

No therapy

eFigure 3. Therapy receipt by age at diagnosis among women with breast cancer in the population-based cohort. 
A

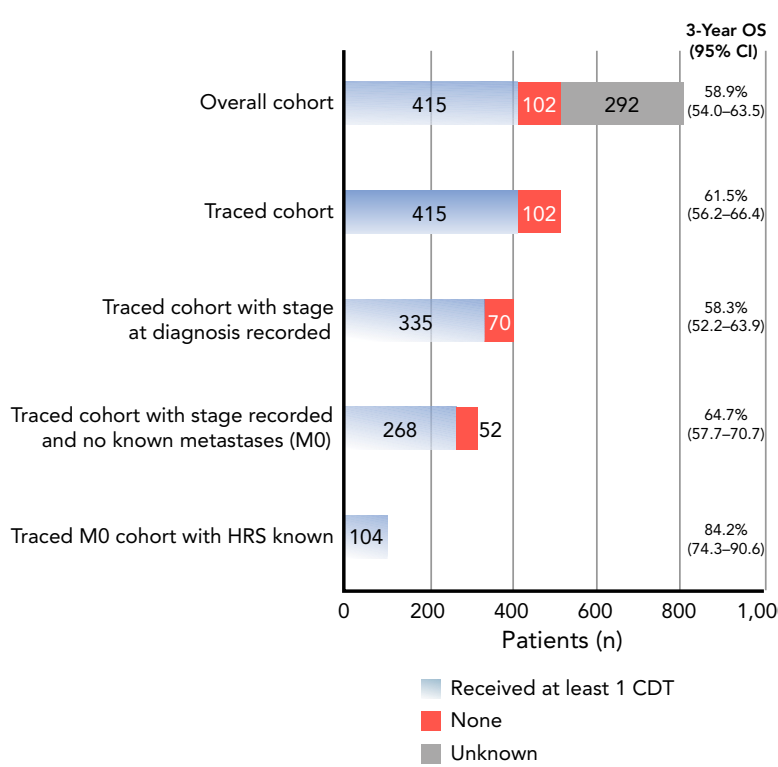

B

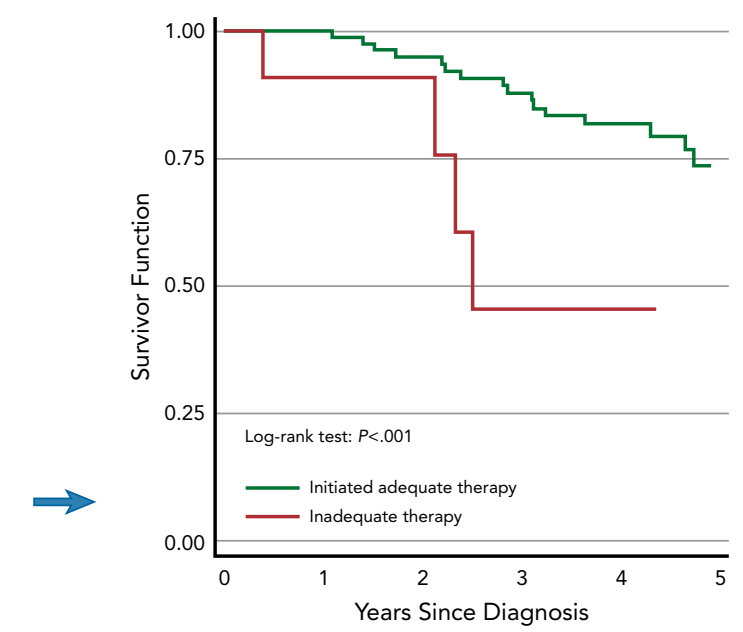

Number at risk Initiated adequate therapy 93 Inadequate therapy 11

eFigure 4. (A) Patient cohorts showing use of at least one type of CDT. (B) OS by therapy among patients with minimum criteria for NCCN therapy evaluation.

Abbreviations: CDT, cancer-directed therapy; HRS, hormone receptor status; OS, overall survival. 


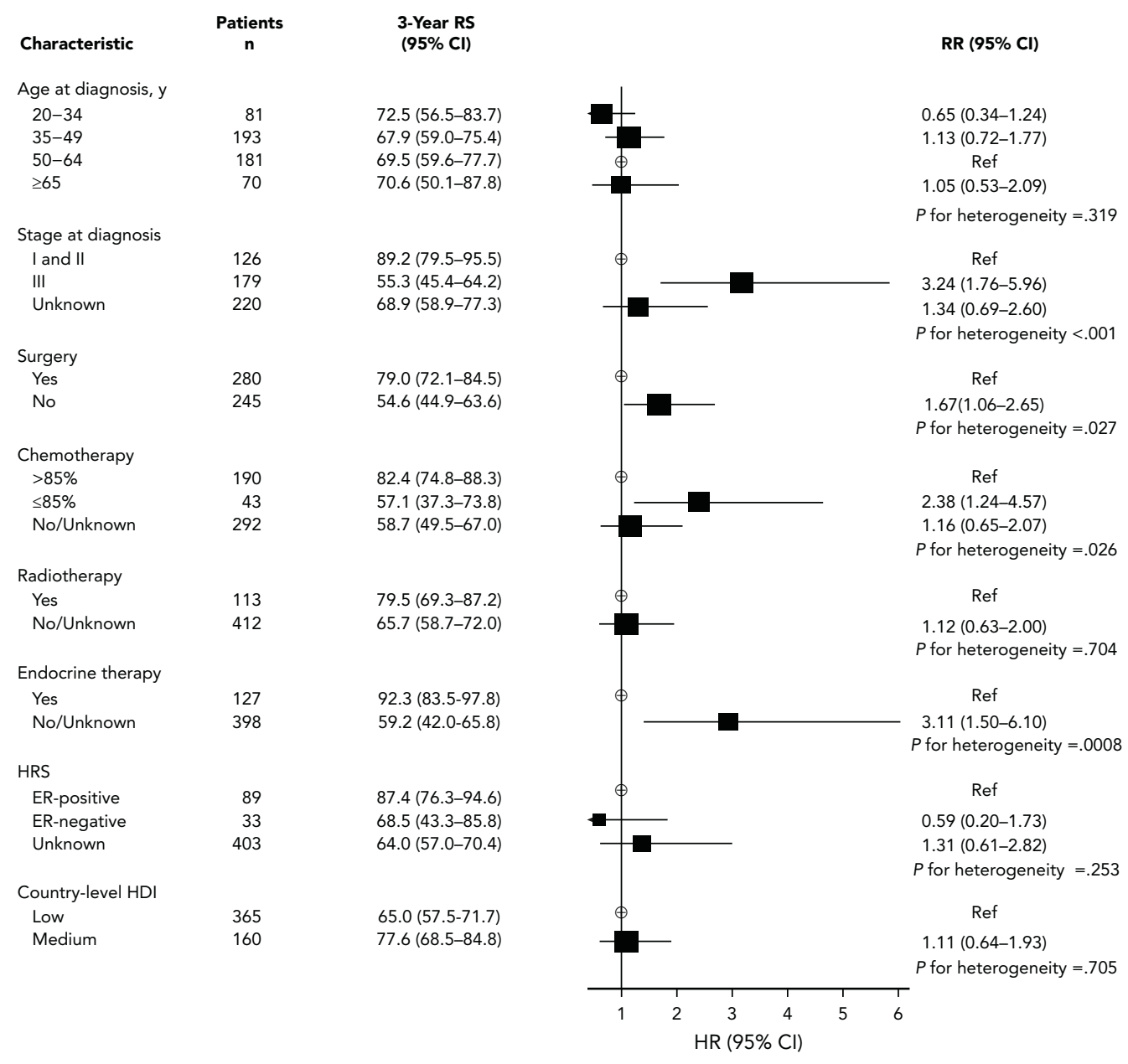

eFigure 5. 3-year RS and excess risk of death from breast cancer among women in the population-based cohort without known metastases and with at least 30 days of follow-up $(n=525)$ adjusted for age, stage, registry area, and country-level HDI.

Abbreviations: ER, estrogen receptor; HDI, Human Development Index; HR, hazard ratio; HRS, hormone receptor status; RR, risk ratio; RS, relative survival. 
eTable 1. Median Age at Diagnosis, Proportion of Deaths, and Loss to Follow-Up in First 3 Years After Diagnosis by Registry Index

\begin{tabular}{|c|c|c|c|c|c|c|c|c|c|}
\hline \multirow[b]{2}{*}{ Registry } & \multirow{2}{*}{$\begin{array}{c}\text { Cases Included } \\
\text { for Survival Analyses } \\
\mathbf{n}\end{array}$} & \multirow{2}{*}{$\begin{array}{l}\text { Median Age } \\
\text { at Diagnosis } \\
y\end{array}$} & \multicolumn{2}{|c|}{ Year 1} & \multicolumn{2}{|c|}{ Year 2} & \multicolumn{2}{|c|}{ Year 3} & \multirow[b]{2}{*}{$\begin{array}{c}\text { Median } \\
\text { Follow-Up y }\end{array}$} \\
\hline & & & $\begin{array}{c}\text { Deaths } \\
\text { n (\%) }\end{array}$ & $\begin{array}{l}\text { LTFU } \\
\text { n (\%) }\end{array}$ & $\begin{array}{c}\text { Deaths } \\
\text { n (\%) }\end{array}$ & $\begin{array}{l}\text { LTFU } \\
\text { n (\%) }\end{array}$ & $\begin{array}{c}\text { Deaths } \\
\text { n (\%) }\end{array}$ & $\begin{array}{l}\text { LTFU } \\
\text { n (\%) }\end{array}$ & \\
\hline Abidjan & 53 & 48 & $3(5.7)$ & $24(45.2)$ & $2(3.8)$ & $5(9.4)$ & $1(1.9)$ & $0(0)$ & 1.0 \\
\hline Addis Ababa & 93 & 44 & $3(3.2)$ & $29(31.2)$ & $7(7.5)$ & $4(4.3)$ & $7(7.5)$ & $4(4.3)$ & 2.7 \\
\hline Bamako & 47 & 45 & $13(27.7)$ & 7 (14.9) & $5(10.6)$ & $3(6.4)$ & $4(8.5)$ & $1(2.1)$ & 1.2 \\
\hline Brazzaville & 75 & 52 & $8(10.7)$ & $51(68.0)$ & $2(2.7)$ & $2(2.7)$ & $2(2.7)$ & $1(1.3)$ & 0.5 \\
\hline Bulawayo & 53 & 57 & 19 (35.8) & $15(28.3)$ & $9(17.0)$ & $2(3.8)$ & $2(3.8)$ & $3(5.7)$ & 0.7 \\
\hline Cotonou & 92 & 47 & $12(13.0)$ & $42(45.7)$ & 8 (8.7) & $3(3.3)$ & $5(5.4)$ & $2(2.2)$ & 0.7 \\
\hline Eldoret & 69 & 47 & $10(14.5)$ & 13 (18.8) & 11 (15.9) & $5(7.2)$ & $2(2.9)$ & $3(4.3)$ & 1.5 \\
\hline Kampala & 42 & 46 & $9(21.4)$ & $11(26.2)$ & $6(14.3)$ & $2(4.8)$ & 5 (11.9) & $0(0.0)$ & 1.0 \\
\hline Maputo & 41 & 49 & $5(12.2)$ & $11(26.8)$ & & & & & 1.3 \\
\hline Nairobi & 55 & 51 & $1(1.8)$ & 19 (34.5) & $4(7.3)$ & $6(10.9)$ & $4(7.3)$ & $1(1.8)$ & 1.8 \\
\hline Namibia & 64 & 52 & $3(4.7)$ & $5(7.8)$ & $2(3.1)$ & $2(3.1)$ & $6(9.4)$ & $1(1.6)$ & 4.7 \\
\hline Total & 684 & 48 & $86(12.6)$ & $227(33.2)$ & $56(8.7)$ & $34(5.3)$ & $38(5.9)$ & $16(2.5)$ & 1.2 \\
\hline
\end{tabular}

Abbreviation: LTFU, lost to follow-up. 